Ann. Biol. anim. Bioch. Biophys., I976, 16 (2), I37-144.

\title{
STAGES OF SEMINIFEROUS EPITHELIAL CYCLE IN THE BUFFALO (BOS BUBALIS)
}

\author{
S. S. GURAYA, and G. S. BILASPURI* \\ Head, Department of Zoology, \\ Punjab Agricultural University, \\ Ludhiana, Punjab (India) \\ * Department of Zoology, \\ College of Basic Sciences and Humanities, \\ Punjab Agricultural University, \\ Ludhiana (India)
}

\section{SUMMARY}

By using PAS-haematoxylin stained preparations of testicular material from mature buffaloes, the process of acrosome development has been distinguished into eighteen steps. The first fourteen steps have been used to distinguish fourteen stages of the seminiferous epithelial cycle (SEC). The first six stages show both (First and second) the generations of spermatids, while the remaining eight stages (VII-XIV) have only second generation of spermatids. $\mathbf{A}_{\mathbf{1}}$-type spermatogonia are present throughout the SEC except stages X-XI, which instead have $\mathrm{A}_{2}$-type spermatogonia. $\mathrm{A}_{\mathbf{3}}$-type spermatogonia occur in stages XII-XIV. Some A-type spermatogonia (i.e. $\mathrm{A}_{0}$ type) divide very rarely. Type $A_{3}$ spermatogonia divide in the stage XIV to produce In spermatogonia which persist upto stage III. In spermatogonia divide between stages III and IV to form $B_{1}$-type spermatogonia which continue to exist upto stage $V$. Between stages $V$ and $V I$, $B_{1}$-type spermatogonia divide to produce $B_{2}$ spermatogonia which in turn divide in the late stage VII to produce the preleptotene spermatocytes. The preleptotene spermatocytes appearing in stage VIII pass through various phases of meiosis and ultimately divide in stage XIV. The spermatids appear in stage I. Frequency of various stages has also been worked out. In order to avoid the discrepancies, the present fourteen stages of PAS-haematoxylin technique have been correlated with the eight stages of haematoxylin-eosin staining reported in the previous paper. For this, frequency and the cellular associations of the stage have been kept in mind. The various stages identified in the buffalo have been compared and contrasted with those of the bull. It is concluded that the development of acrosome together with the shape and size of the developing spermatid nucleus is a better method for the identification of stages, which can be used in the experimental treatments and also in the immature and mature mammals. The correlations of various stages identified with two different criteria help in the better identification of spermatogonia and spermatocytes which in turn can be used for the identification of stages of SEC in the absence of spermatids. 


\section{INTRODUCTION}

The histological organization of the seminiferous epithelium has been described previously for different mammalian species (Courot et al., I970 ; CLERMONT, I972 ; BERndTSON and Desjardins, I974; Swierstra et al., I974). Guraya (I965) described acrosome formation in the sheep, goat and buffalo. To the best of our information, no work has been done previously on the kinetics of spermatogenesis in the buffalo, which is essential to assess the effects of environmental factors on its spermatogenesis and spermatozoa. Keeping this in view, the present study using periodic acid-Schiff (PAS)/haematoxylin technique was initiated to follow the stages of seminiferous epithelial cycle (SEC) in the buffalo. On the basis of actosome formation, as well as shape and size of the developing spermatid nucleus, fourteen stages (I-XIV) of its SEC have been distinguished. $P$. roo frequency of the stages has also been worked out. An attempt has also been made to correlate the stages of PAS/haematoxylin preparations with those of haematoxylin-eosin preparations reported in the previous paper (GURAYA and BILASPURI, I976 $a$ ). For this purpose, p. Ioo frequency and cellular associations of the stages have been taken into consideration.

\section{MATERIAL AND ME'THODS}

Testicular material from the sexually mature buffalo bulls was used for the present investigation. It was obtained from the slaughter houses of Uttar Paradesh and Delhi as well as from the clinics of Punjab Agricultural University, Ludhiana (India). Testicular biopsies were also obtained in some cases. Material in each case was put in physiological saline solution and then cut into small pieces which were immediately fixed in sufficient volume of Zenker formol. After fixation, the material was stained by the PAS technique (as cited in PEARse, I968). Some of the PAS-stained sections were also counterstained with iron haematoxylin. Sections after staining and dehydration were mounted in DPX or Canada balsam.

\section{RESULTS}

With PAS/haematoxylin, the acrosome formation has been distinguished into I8 steps (fig. I). First I4 steps are used to identify fourteen stages of SEC. The older elongated spermatids (i.e. first generation of spermatids) are found only in first six stages (fig. 2). Type $A_{0}$ spermatogonia are present in all the stages (fig. 2). The datailed morphology of various spermatogenic cells has been described previously (Guraya and BILASPURI, I976 b). Type $A_{1}$ spermatogonia appear to be present throughout SEC except stages $\mathrm{X}$ and XI. The cellular composition of various stages is summarized in figure 2 .

\section{Stage $I$}

Begins with the end of maturation division of secondary spermatocytes and formation of a new group of spermatids having no proacrosomal granules or vacuoles 
(step r). From the basement membrane towards tubular lumen, there are seen intermediate (In) spermatogonia, I or 2 rows of primary spermatocytes at late zygotene phase followed by 2 or 3 rows of newly formed spermatids (step I). Older elongated spermatids at step I5 $_{5}$ are also present (fig. 2).

\section{Stage II}

Begins with the appearance of two or three proacrosomal granules surrounded by proacrosomal vacuoles in the idiosome of younger round spermatids (step 2). In spermatogonia of stage I remain as such. Primary spermatocytes at early pachytene stage arranged in $I$ or 2 rows are present next to spermatogonia. They are followed by 2 or 3 rows of step 2 spermatids and older elongated spermatids of step $I 6$. Older spermatids are still connected with the Sertolian cytoplasm (fig. 2).

\section{Stage $I I I$}

Begins with the fusion of proacrosomal granules (step 3). Spermatogonia, primary spermatocytes and older spermatids are at the same stage as described for stage II (fig. 2).

\section{Stage IV}

Begins with the placement of acrosomal granule on the nuclear envelope and subsequent spreading of acrosomal vacuole (step 4). In-spermatogonia of stage III have divided to form $B_{1}$ spermatogonia. Early pachytene spermatocytes have transformed into mid pachytene spermatocytes. Spermatids of step 4 are arranged in 3 or 4 rows followed by spermatids of older generation (step i7) towards tubular lumen (fig. 2).

\section{Stage $V$}

Begins with the formation of concavity in the spermatid nucleus due to acrosomal vacuole growth. $B_{1}$ spermatogonia of stage IV remain as such. Primary spermatocytes remain at mid pachytene, which are followed by 2 or 3 rows of round spermatids of step 5 in which are also found older spermatids of step 18 . The latter migrate towards the tubular lumen in the form of bundles. In the older spermatids of step I8, the intensity of PAS-staining appears to decrease. The residual bodies lie among these spermatids (fig. 2).

\section{Stage VI}

Begins with the spreading of acrosomal granule and vacuole over anterior portion of the nucleus for a small distance (step 6). $B_{1}$ spermatogonia of stage $V$ divide to form $B_{2}$ spermatogonia. Primary spermatocytes are at mid pachytene stage. Younger round spermatids are placed in 2 or 3 rows followed by spermatids of older generation (step I8) which are compactly arranged in one row at the inner edge of seminiferous tubule. These immature spermatozoa after the elimination of their residual cytoplasm are ready for release into lumen (fig. 2). 


\section{Stage VII}

Begins with the extension of acrosomal cap to one third of nucleus (step 7). $\mathrm{B}_{2}$ spermatogonia and their mitotic figures are visible. Spermatocytes are arranged in $I$ or 2 rows. Some primary spermatocytes at mid pachytene have transformed to late pachytene. Only one generation of spermatids (i.e. step 7) is present. Generally, older or first generation of spermatids is not present. Sometimes, a few immature spermatozoa at step I 8 are seen in the process of their release. Residual bodies have moved towards the Sertoli cell (fig. 2).

\section{Stage VIII}

Begins with the posterior extension of acrosomal cap upto one half of spermatid nucleus (step 8). Instead of $\mathbf{B}_{\mathbf{2}}$ spermatogonia, which have already divided, there are seen preleptotene spermatocytes followed by $\mathrm{I}$ or 2 rows of older spermatocytes at late pachytene stage. Residual bodies are being engulfed by the Sertoli cells (fig. 2).

\section{Stage $I X$}

Begins with the disappearance of acrosomal vacuole (step 9). Newly formed spermatocytes arranged in I or 2 rows show "leptotene in grains " and leptotene proper stages. Older primary spermatocytes arranged in 2 or 3 rows remain at the pachytene stage (fig. 2).

\section{Stage $X$}

Begins with the elongation and flattening of spermatid nuclei, acrosome has increased in size (step Io) in comparison to stage IX; some $A_{1}$ spermatogonia of stage IX have divided to form $\mathrm{A}_{2}$ spermatogonia which show relatively darker chromatin than $A_{1}$ spermatogonia. Younger spermatocytes arranged in $I$ or 2 rows remain at the granular leptotene stage. They are followed by older spermatocytes having their pachytene advanced to early diplotene stage (fig. 2).

\section{Stage $X I$}

Begins with the spermatid phase when acrosome is further increased in size (step II). Spermatid nucleus is also more elongated. Older primary spermatocytes remain at early diplotene stage as in stage $X$ but younger ones are at late leptotene or early zygotene stage. $A_{2}$ type spermatogonia of the stage $\mathrm{X}$ are also present. They are undergoing mitosis in some parts of seminiferous epithelium (fig. 2 ).

\section{Stage $X I I$}

Begins with the spermatids in which the acrosome is further increased in size and nucleus is more elongated (step I2). They are organized in bundles into the Sertolian cytoplasm. Older primary spermatocytes are at the same stage as in stage XI but younger spermatocytes previously at early zygotene are advanced to late zygotene. $A_{2}$ spermatogonia have divided to form $A_{3}$ spermatogonia (fig. 2). 


\section{Stage XIII}

Begins with the spermatids having maximum size of their acrosome and nucleus (step I3). Primary spermatocytes previously at early diplotene stage have increased in size and are at late diplotene or in "diakinesis "; but younger ones remain at zygotene sage. $A_{3}$ spermatogonia are also seen in the process of mitotic division (fig. 2).

\section{Stage $X I V$}

Begins with spermatids having apical part of their acrosome relatively decreased in size and their nucleus attained almost the spatula-like shape (step I4). Older primary spermatocytes being either at late diplotene or at diakinesis, form secondary

TABLE I

Correlations of stages of SEC classified separately with haematoxylin-eosin and PAS-haematoxylin in the buffalo

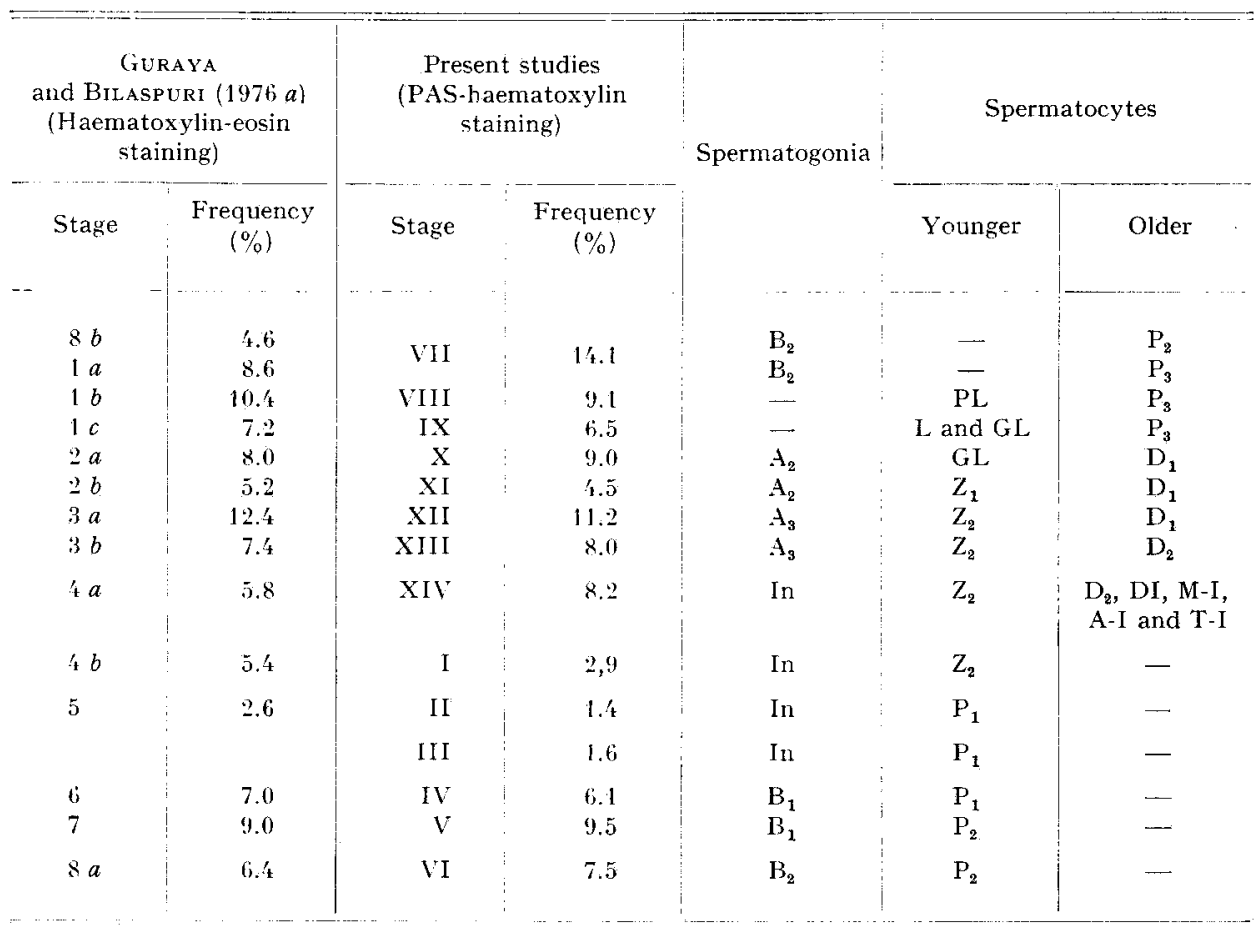

Lettering: $A_{2}$, type $A_{2}$ spermatogonia ; $A_{3}$, type $A_{3}$ spermatogonia ; In, Intermediate spermatogonia ; $B_{1}$, type $B_{1}$ spermatogonia; $B_{2}$, type $B_{2}$ spermatogonia; $P L$, preleptotene; $L$, proper leptotene; $G L$, granular leptotene; $Z_{1}$, early zygotene; $Z_{2}$, late zygotene, $P_{1}$, early pachytene, $P_{2}$, mid pachytene; $P_{3}$, late pachytene; $D_{1}$, early diplotene $: D_{2}$, late diplotene ; DI, diakinesis ; M-I, metaphase-I ; A-I, anaphase-I, T-I, telophase-I; - not present.

Note: Type $\mathrm{A}_{\mathbf{0}}$ spermatogonia are present in all the stages classified with the two different criteria. Type $A_{1}$ spermatogonia also appear throughout S.EC except stages X-XI. 
spermatocytes after passing through metaphase, anaphase and telophase of first meiotic division. It is only in this stage that the secondary spermatocytes of second meiotic division showing different stages are present. This results in the formation of younger spermatids of stage I. Older spermatocytes arranged in one or two rows are at zygotene stage. $A_{3}$ spermatogonia of stage XIII have divided to form intermediate spermatogonia (fig. 2).

\section{P. 100 frequency of the stages of $S E C$}

The examination of seminiferous tubules has shown that the spermatogenic cells in a seminiferous tubule were at or almost at one stage. Therefore, to work out the $p$. Ioo frequency, the number of seminiferous tubules for different stages was added after studying several serial sections. However, stages I, II and III were exceptions. Stage I was present in association with stage XIV. Out of the total seminiferous tubules at stage XIV, almost $50 \mathrm{p}$. Ioo of them were occupied by stage I for approximately half of their area. Besides occurring in different seminiferous tubules, stages II and III also occurred in the same seminiferous tubule. Here, approximately half of the area of seminiferous tubule was occupied by either of them. So keeping this in view, half of the frequency of such seminiferous tubules was counted for each of stages II and III. So, on the whole, there was no neccesity for using the " so-called paper cut method " described by CI.ERMONT (I963) for the human. In this way, the frequency for all the stages was worked out. From this, p. roo frequency for each stage (table I) was calculated.

\section{DISCUSSION}

Stage XIV in the buffalo appears to correspond to stage XII of the bull (BERNDTSON, I972 ; BERNDTSON and DESJARDINS, I974). This is due to the presence of (I) secondary spermatocytes of very short duration and (2) zygotene spermatocytes, in them. In their cellular associations, stages I-VII of the buffalo resemble the corresponding stages in the bull. The stages VIII and IX in the buffalo actually represent the stage VIII of the bull described by BERNDTSON and DESJARDINS (I974) who seem to have missed the stage corresponding to the stage IX of this study as they have not identified the proper leptotene and granular leptotene in their stage VIII. Moreover, there is very little difference in the extension of acrosome between steps 8 and 9 (fig. I, 2) of the buffalo and the head cap present in step 8 disappears in step 9. The second stage apparently missed by BERNDTSON (I972) ; BERNDTSON and DESJARDINS (I974) in the bull may be either stage $\mathrm{X}$ or XI of the buffalo. This is due to the fact that they have not made any distinction between granular leptotene and late leptotene (or early zygotene) which seem to be represented by their leptotene. A very small increase is seen in the anteriorly protruding portion of the acrosome in step II than in step Io (fig. I) but the nucleus is relatively more elongated in the former. The changes observed in the acrosome system of the developing spermatid nucleus from steps 8 to II of the buffalo may also be expected to occur in the bull, which have not been followed by BERNDTSON and DESJARDINs (1974). The changes in the proper leptotene, granular leptotene, and 
late leptotene (or early zygotene) observed in the buffalo have also been reported in the bull by Hochereau De REviers (I970). Therefore, BERNDTSON (I972); BERND'TSON and DESJARDINS (I974) might have missed two stages in their studies as already discussed.

If each substage of GURAYA and BILASPURI (I976a) is considered to be equivalent to a separate stage, the criterion of classification based on haematoxylin eosin technique also leads to the identification of fourteen different stages. The advantage of PAS-haematoxylin method is that the stages of SEC can be distinguished in the complete absence of older elongated spermatids (i.e. steps $\mathrm{I} 5-\mathrm{I} 8$ in the buffalo) and also in the presence of only a small number of younger spermatids (i.e. steps I-I 4 in the buffalo). Table I will help in a longway in making these required modifications in the identification of stages under different experimental treatments which do affect the seminiferous epithelium (SwIERSTRA et al., I964; STEINBERGER, I97I ; CLERMONT, I972). It will be of special use for the identification of cellular associations in the immature buffaloes in farm animals especially the buffalo. The division of zygotene and diplotene into their early and late stages, and of pachytene into its early, mid and late stages will further help us for the better identification of spermatocytes and stages of SEC.

Reçu pour publication en août 1975.

\title{
RÉSUMÉ \\ STADES DU CYCLE DE L'ÉPITHÉLIUM SÉMINIFÈRE CHEZ LE BUFFLE (BOS BUBALIS)
}

\begin{abstract}
Dans une étude précédente, par une coloration hématoxyline-éosine, nous avions défini huit stades de l'épithélium séminifère. Ici, en utilisant une coloration PAS-hématoxyline, nous distinguons I4 stades. Pour le développement de l'acrosome, on distingue i 8 étapes. Les $\mathrm{I}_{4}$ premières sont utilisées pour définir les I 4 stades du cycle de l'épithélium séminifère. Les 6 premiers stades présentent 2 générations de spermatides, les 8 autres la seconde génération seulement. Les spermatogonies $\mathrm{A}_{1}$ sont présentes à tous les stades sauf les stades X et XI, caractérisés par la présence des spermatogonies $A_{2}$. Les spermatogonies $A_{3}$ apparaissent aux stades XII-XIV. Certaines spermatogonies $A$ (type $A_{0}$ ) se divisent très rarement. La division des spermatogonies $A_{3}$ au stade XIV donne les spermatogonies intermédiaires (In) qui persistent jusqu'au stade III. Elles se divisent entre les stades III et IV pour donner les spermatogonies $B_{1}$ présentes jusqu'au stade V. Celles-ci se divisent entre les stades V et VI pour donner les spermatogonies $B_{2}$ qui se divisent elles-mêmes à la fin du stade VII pour donner les spermatocytes (préleptotène) qui, apparus au stade VIII, traversent toutes les phases de la mé̈ose et se divisent finalement au stade XIV. Les spermatides apparaissent au stade $\mathrm{I}$. On a étudié la fréquence des différents stades et comparé les résultats avec ceux de la première étude (tabl. I). L'utilisation de deux critères, le développement de l'acrosome et la forme et la taille du noyau de la spermatide, pour définir les stades de l'épithélium séminifère, permet une meilleure identification des spermatogonies et spermatocytes qui peuvent être à leur tour utilisés pour identifier les stades de l'épithélium séminifère en l'absence de spermatides.
\end{abstract}

\section{REFERENCES}

Berndtson W. E., 1972. Stages of the cycle of the seminiferous epithelium in the bovine. Biol. Reprod., 7, 129 (abstr.).

Berndtson W. E., Desjardins C., I974. The cycle of the seminiferous epithelium and spermatogenesis in the bovine testis. Amer. J. Anat., 140, 167-r8o. 
Clermont $Y .$, I963. The cycle of the seminiferous epithelium in man. Am. J. Anat., 112, 35-5t.

Clermont $Y$. , I972. Kinetics of spermatogenesis in mammals : Seminiferous epithelium cycle and spermatogonial renewal. Physiol. Rev., 52, 198-236.

Courot M., Hochereau de Reviers M. T., Ortavant R., ig7o. Spermatogenesis. In : A. D. Johnson, W. R. Gomes and N. L. Vandemark. The Testis, Vol. I, 339-432, Academic Press, New York.

GuRAYA S. S., I965. Histochemical studies on spermateleosis in sheep, goat and buffalo. La Cellule, 65, 367-373.

GurayA S. S., Bilaspuri G. S., I976 a. Stages of seminiferous epithelial cycle and relative duration of spermatogenic processes in the buffalo (Bos bubalis). Morph. Jb. (In press).

Guraya S. S., Bilaspuri G. S., I976 b. Spermatogenic cells of the buffalo (Bos bubalis) testis. Indian. J. Ani. Sci. (In press).

Hochereau De REviers M. T., I97o. Etude des divisions spermatogoniales et du renouvellement de la spermatogonie rouche chez le Taureau. Dr. Sc. Thesis Paris.

Pearse A. G. E., I968. Histochemistry, theoretical and applied, Vol. I, J. and A. Churchill, Ltd., London.

Steinberger E., r97r. Hormonal control of mammalian spermatogenesis. Physiol. Rev., 51, I-22.

Swierstra E. E., Gebauer M. R., Pickett B. W., 1974. Reproductive physiology of the stallion : I. Spermatogenesis and testis composition. J. Reprod. Fert., 40, II3-23.

Swierstra E, E., Whitefield J. W., Foote R. H., 1964. Action of amphotericin B (fungizone) on spermatogenesis in the rabbit. J. Reprod. Fertil., $7,13-19$.

\section{PLATE I}

FIG. I

Diagrammatic drawings of different steps of spermiogenesis, prepared from the combined observations on the PAS and haematoxylin-eosin stained preparations. Numbers I-I8 refer to spermatids at different steps of spermiogenesis, which consists of four phases i.e. Golgi phase (steps I-3), cap phase (steps 4-8), acrosome phase (steps 9-I4) and maturation phase (steps $\mathrm{I}_{5}$-I8).

Lettering: I, idiosome; PAG, proacrosomal granule; PAV, proacrosomal vacuole; $\mathrm{AG}$, acrosomal granule; AV, acrosomal vacuole ; $M C$, manchette ; $A$, acrosome ; $\mathrm{HC}$, head cap ; NE, neck ; CD, cytoplasmic droplet; M, middlepiece; AN, annulus; T, Tail. 


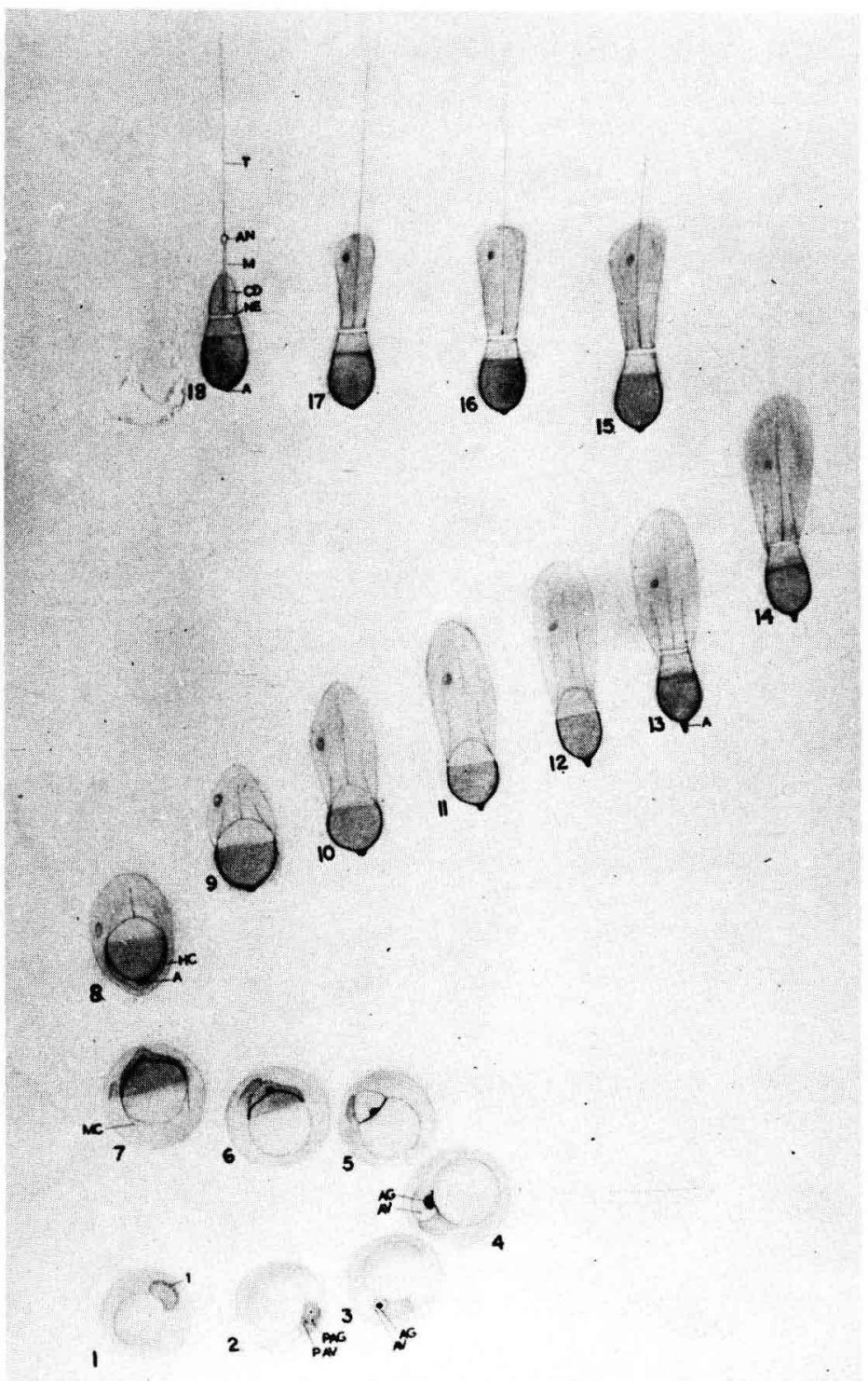

S. S. GURAYA and G. S. BILASPURI 


\section{PLATE II}

FIG. 2

Cellular composition of the 14 stages of the seminiferous epithelial cycle in the buffalo. Each column (I to XIV) shows the germinal cells in a given cellular association. The associations or stages are identified by the first 14 out of the 18 steps of spermiogenesis. The latter are defined by the morphological changes in the nucleus (light shaded) and in the acrosomic structure (dark grey) of the spermatids as seen in periodic acid-Schiff/haematoxylin staining.

Lettering : $\mathbf{A}_{0}$, type $\mathbf{A}_{0}$ spermatogonia ; $\mathbf{A}_{1}, \mathbf{A}_{2}$ and $\mathbf{A}_{3}$ represent three types of type $A$ spermatogonia. In, intermediate spermatogonia, $\mathrm{B}_{1}$ and $\mathrm{B}_{2}$, two types of type $\mathrm{B}$ spermatogonia ; PL, preleptotene; $L$, proper leptotene, $G L$, granular leptotene; $Z_{1}$ and $Z_{2}$, early and late zygoter:; $P_{1}, P_{2}$ and $P_{3}$, early, mid and late pachytene $; D_{1}$ and $D_{2}$, early and late diplotene; SPII, secondary spermatocytes. $M$, close to the spermatogonium means mitosis. 


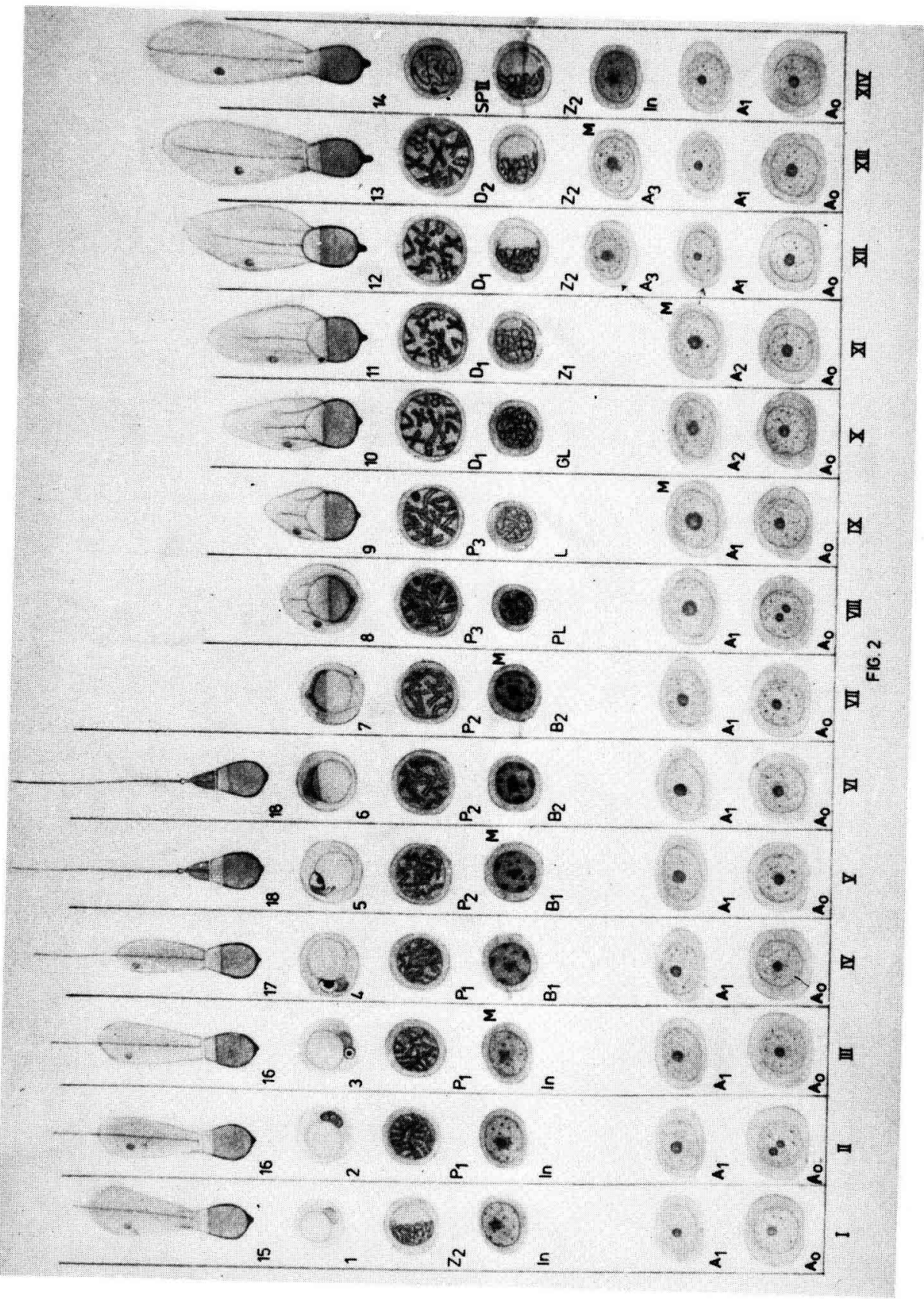

